\title{
Demystification of GM crop costs: releasing late blight resistant potato varieties as public goods in developing countries
}

\author{
Benjamin Schiek \\ Sub-Saharan Africa Regional Office, \\ International Potato Center, \\ P.O. Box 25171, Nairobi 00603, Kenya \\ Email: ben.schiek@gmail.com
}

\section{Guy Hareau}

Social and Health Sciences, International Potato Center, P.O. Box 1558, Lima 12, Peru

Email: G.Hareau@cgiar.org

\section{Yona Baguma}

National Agricultural Research Organization, P.O. Box 295, Entebbe, Uganda

Email: baguma1234@yahoo.com

\section{Akshat Medakker \\ Sathguru Management Consultants Pvt. Ltd., Plot 54, Sagar Society, Road No 2, \\ Banjara Hills, Hyderabad - 500034, India \\ Email: akshatm@sathguru.com}

\section{David Douches}

Department of Plant, Soil and Microbial Sciences, Michigan State University,

East Lansing, MI 48824, USA

Email: douchesd@gmail.com

\section{Frank Shotkoski}

International Programs, College of Agriculture and Life Sciences

214 Rice Hall, Cornell University,

Ithaca, NY 14853, USA

Email: fas23@cornell.edu 


\title{
Marc Ghislain*
}

\author{
Sub-Saharan Africa Regional Office, \\ International Potato Center, \\ P.O. Box 25171, Nairobi 00603, Kenya \\ Email:m.ghislain@cgiar.org \\ *Corresponding author
}

\begin{abstract}
A few studies have reported some of the costs associated with bringing to market genetically-modified (GM) crops but no comprehensive studies exist on the real cost of the entire process of developing and releasing one GM variety by a not-for-profit institution in a developing country for sustainable agriculture. Despite the lack of documented studies, it is commonly assumed that such an undertaking is cost prohibitive, based on mere hearsay, and on two private sector cost assessments. The present study assesses the costs and the time expenditures to two not-for-profit programs, one lead by CIP and the other by Cornell University, of developing a late blight resistant $(\mathrm{LBr})$ potato variety for release in one developing country. CIP's costs run to $\$ 1.6$ million over eight years, while Cornell's costs amount to $\$ 1.4$ million over nine years. Exogenous disturbances might result in insignificant increases in cost, but can increase time expenditure significantly. A sensitivity analysis revealed that the total cost is markedly influenced by technical parameters determining the production and identification of the pre-commercial $\mathrm{LBr}$ transgenic event.
\end{abstract}

Keywords: GM crop; transgenic crops; cost; not-for-profit institution; potato; late blight resistance; $\mathrm{LBr}$; developing country.

Reference to this paper should be made as follows: Schiek, B., Hareau, G., Baguma, Y., Medakker, A., Douches, D., Shotkoski, F. and Ghislain, M. (2016) 'Demystification of GM crop costs: releasing late blight resistant potato varieties as public goods in developing countries', Int. J. Biotechnology, Vol. 14, No. 2, pp.112-131.

Biographical notes: Benjamin Schiek is a young Agricultural Economist who collected and analysed the data of this study. His main research interest is on ex-ante climate change socio-economic impact assessment relevant to sustainable agriculture, forestry and natural resource economics.

Guy Hareau is a Senior Agricultural Economist who has studied economic benefits of GM crops in developing countries. His main research interest is defining priorities for research and impact assessment of agricultural technical change.

Yona Baguma is the Deputy Director General at the National Agricultural Research Organization (NARO) of Uganda. His research interest is the development and safety assessment of GM crops to benefit Ugandan farmers and beyond.

Akshat Medakker is the Associate Vice President at Sathguru Management Consultants in India. His main interest is to facilitate innovation management and create global partnerships to mobilise technologies for sustainable development.

David Douches is a Professor and Director of the Potato Breeding and Genetics Programs. His main research interest is breeding for disease and insect resistance and potato quality, molecular markers, application of transformation to potato breeding, and gene mapping. 
Frank Shotkoski has 20 years of academic and industrial experience in both agriculture and medical biotechnology. His main interest is to introduce agriculture biotechnology products for economic development of farmers in developing countries.

\begin{abstract}
Marc Ghislain is a Senior Biotechnology Researcher with 20 years of working experience in developing countries. His research interest is to develop GM potato and sweet potato with traits relevant to small-holder farmers in developing countries.

This paper is a revised and expanded version of a paper entitled 'Cost analysis of producing a transgenic late blight resistant potato variety by non-profit institution reveals much lower cost than that of the private sector' presented at the ISBGMO13, Cape Town, South Africa, 9-13 November 2014.
\end{abstract}

\title{
1 Introduction
}

The cost of developing and releasing a genetically-modified (GM) variety is generally believed to be on the order of tens, if not hundreds, of millions of US dollars; but this belief is unsupported by documented studies. While the benefits of GM crops have been widely assessed and documented (Brookes and Barfoot, 2012; Klumper and Qaim, 2014), development costs have always been considered either as sunk, or have been assessed using secondary data or expert opinions with no direct access to the real costs incurred by the technology developers. Many influential people within development organisations, including donors to the CGIAR, a not-for-profit research organisation for agriculture development in developing countries, tend to assume that such costs are prohibitive; and the only two widely available studies on this subject would justify this assumption. The first study estimates the cost of deregulation alone at \$7-15 million (Kalaitzandonakes et al., 2006). The second study, developed by a consultancy firm commissioned by Crop Life International, puts the whole cost, from discovery to deregulation and release, at USD \$136 million, with a standard deviation of \$85.6 million (McDougall, 2011).

However, these studies are based on surveys of anonymous experts at private sector corporations, and thus focus on the development of high value trait products such as herbicide-tolerant corn for simultaneous deregulation and release in many developed countries. Additionally, government regulation and public opposition in a recent set of field trials in Switzerland more than doubled the costs of doing the research (Bernauer et al., 2011). It stands to reason that the costs to not-for-profit institutions pursuing the development of low economic value trait products for deregulation and release in one or two developing countries will be much lower. One study reports, for example, that the deregulation of viral resistant rice in Costa Rica costs $\$ 2.25$ million; and that the deregulation of Bt eggplant in India costs $\$ 53,556$ (Falck-Zepeda et al., 2012). Another study estimated the total cost of developing Bt corn MON810 in the Philippines at \$2.6 million using indirect cost methodology used by the pharmaceutical industry (Manalo and Ramon, 2007). These sums are very small compared to those reported in the private sector studies. What about the whole cost to not-for-profit institutions of all the processes involved in the development, deregulation, and release of a low-value trait 
product? Are such endeavours comparable to private sector aims and activities, or are they a different sort of undertaking?

The present paper provides an answer to this question through a case study of the costs to not-for-profit institutions of developing a specific GM product for deregulation and release as a public good in a specific developing country. The specific GM product considered in this paper is a potato variety with resistance to late blight disease mediated by $R$ genes [late blight resistance ( $\mathrm{LBr}$ ) potato].

The pathogen Phytophthora infestans $(\mathrm{Pi})$ is the causal agent of the potato late blight disease known to be responsible for the great Irish potato famine of the $1840 \mathrm{~s}$ and remains a potato destroyer (Fry, 2008). This disease is still a major problem in developing countries, responsible for an average potato yield loss of $15 \%$, or USD 10 billion annually, when fungicide expenditures are taken into account (Haverkort et al., 2009). The conventional farmer's defence of treating the potato crop with pesticides is costly and is gradually rendered ineffective since the pathogen can develop resistance to such measures. Some potato varieties exhibit a natural, partial resistance to late blight, but still require at least some pesticide spraying; and the durability of their resistance is under question.

Current GM strategies to control this devastating disease includes stacking through transgenesis broad-spectrum resistance $(R)$ genes isolated from wild potato relatives (Song et al., 2003; Zhu et al., 2012). This approach holds great appeal among potato breeding programs and companies worldwide since the genetic modification is achieved using genuine potato genes, and should consequently face less opposition during the deregulation and release process (Haverkort et al., 2008; Jo et al., 2014). As a matter of fact, one of such kind (cigenic/intragenic) potato is the innate potato which was deregulated recently in the USA. The economic and environmental benefits of potato with late blight resistance have been documented also for developing countries (Adiyoga, 2009; Islam and Norton, 2007; Selvaraj, 2007). The strategy has now been tested with favourable results in confined field trials in numerous countries, including Indonesia, Bangladesh, India, USA and five European countries (Kuhl et al., 2007; Halterman et al., 2008; Ambarwati et al., 2013; JRC, 2015).

The cost analysis developed in this study is constructed around the specific costs of real product development, risk assessment, and deregulation. The not-for-profit institutions participating in this study each completed, independently, their own cost assessments using a common template which explicitly accounts for assumptions about critical parameters (such as the transformation efficiency of the target variety), and for any unplanned exogenous disturbances which could raise costs. The study recorded also the time needed for completing each process.

Wherever possible, effort is made to ensure that homogenous processes are being compared, and to clarify any sources of variance between the institutions' cost assessments. Cost components with unclear or highly subjective definitions are excluded from the cost assessment. Whereas the McDougall's (2011) study included assessment of a 'discovery' phase (which accounted for $22 \%$ of the mean total cost), the present study excludes such a phase because

1 what exactly constitutes such a phase, when it begins and ends, is essentially arbitrary 
2 the participating institutions acquired the $R$ gene technology free-of-charge and thus

incurred none of the costs associated with its original discovery and development.

Moreover, whereas the private sector survey was based on the costs of developing any single crop trait product for release in any number of markets for any end-use (McDougall, 2011), this study is confined to the development of a single $\mathrm{LBr}$ potato variety for release in a single market in the developing world. Such a program is representative of the scale and aims of not-for-profit GM product development initiatives, and yet is also specific enough to ensure comparability among the cost assessments completed by the participating not-for-profit institutions.

The present study is thus unique in its scope, comparing the development of the same crop/trait combination in different institutions of similar mandate targeting similar regions. It is also the first of its kind as regards the methodological detail followed to describe the processes involved in the development and release of the trait product, allowing for more precise identification and comparison of trait-specific costs across the institutions.

\section{Methodology}

\subsection{Participating not-for-profit institutions}

The not-for-profit institutions participating in this study have established partnerships lead by the International Potato Center (CIP) and Cornell University (CU). In CIP's case, $\mathrm{LBr}$ potato development has taken place with the development of transgenic events at CIP' laboratories followed recently by a partnership with Uganda's National Agricultural Research Organization for future field trials and associated environmental risk assessment.

At $\mathrm{CU}$, the $\mathrm{LBr}$ potato development program is one of the $\mathrm{GM}$ products of the USAID-funded ABSPII program, and is based on a transgenic event originally developed at the University of Wisconsin. However, in the CU cost assessment, the Michigan State University (MSU) potato biotechnology team was chosen to estimate the costs of developing pre-commercial $\mathrm{LBr}$ candidate events, based on their long-standing experience in potato genetic engineering. $\mathrm{CU}$ is directly responsible for assessing the costs of wide area testing and regulatory approval of $\mathrm{LBr}$ potato which are under its management in India and Indonesia, (in partnership with Sathguru Management Consultants Pvt. Ltd., India).

These institutions each completed their own cost assessments using a common template which is described below. At the time of this study (summer to fall 2013), both institutions were at different stages of development of their product. CU is already engaged in the large area testing for trait stability and environmental studies while CIP is still at the stage of first confined field trials. Hence, the cost and duration for each of the steps involved in production and deregulation of one LB resistant commercial variety are estimated based on current costs of personal, operations in laboratories and field and institution indirect costs. 


\subsection{Scope}

The present study was structured with a well-defined scope and processes to minimise double counting of costs and allow for comparative analyses being conducted.

In the first place, the scope is technology- and geographic-specific. This is a study on the costs to not-for-profit institutions of developing a single $\mathrm{LBr}$ potato variety for cultivation approval only in a single developing country.

Secondly, the costs of the so-called 'discovery phase' are excluded from this study. The cost assessment begins at the clearly defined milestone where the proof-of-concept is completed and the technology is ready for product development. In the case of $\mathrm{LBr}$ potato, that means that the gene sequence, including its regulatory elements, the method of transformation, the expected level of expression in the target organ, the stage of development of the plant, and the trait assessment, are all known. Thus, none of the costs associated with research and development of the gene constructs or of testing them in transgenic events are included (cloning and testing different $R$ genes, testing the durability of LB resistance, evaluating different strategies for deployment, socioeconomic targeting studies, communicating the results to stakeholders, and building biotechnology and biosafety facilities). Also excluded are the costs of building the capacity of partners, scientific publications, and participation in scientific conferences apart from any such activities strictly needed for the LBr product development. The costs of obtaining freedom-to-operate and/or intellectual property rights over the relevant technology are also excluded. It is assumed that these issues and costs have been dealt with at the previous stage of the proof-of-concept and has defined which technology element will be eventually used for product development.

\subsection{Opportunity cost}

The opportunity cost of forgoing alternative investments is also excluded from this study. This is partly to preserve comparability with the private sector study, which also ignored opportunity costs. However, the main reason for excluding opportunity cost is that this study is meant to be representative of GM programs for which there are currently no known alternative substitutes. For example, there is currently no non-GM method of introducing LB resistance into commonly consumed potato varieties. A marker assisted breeding program might, after a long period of cross-breeding, produce a completely new variety of potato with some level of resistance to LB, but then the question remains as to whether the resistance level is comparable to what can be achieved through a GM method, and whether this new variety can replace the existing common varieties that are in high demand. In this sense, then, there are no real alternative investment opportunities which can be forgone, and thus no opportunity cost.

One can argue, moreover, that the relative risks and drawbacks associated with GM and non-GM alternatives are offsetting, resulting in an opportunity cost that is close to zero. For example, a non-GM breeding program would certainly face less political opposition and thus move through regulation and release phases more rapidly as compared with a GM program; but these gains are offset by the relatively long time horizon associated with such methods, and a relatively high risk that the method might not even produce the desired results. 


\subsection{Processes}

The processes that are included in this cost assessment were defined at the beginning of this study in a guidelines document based on interviews with lab technicians, research associates, principal investigators, and regulatory officials who have experience in such product development and associated processes. The document divides $\mathrm{LBr}$ potato development and release into four processes:

1 pre-commercial candidate event production and selection

2 wide area testing through multi-location confined field trials

3 compilation of the regulatory dossier

4 registration and regulatory affairs.

Each of these is further divided into sub-processes. Each sub-process line item is then broken down into conventional accounting categories, i.e., operational staff costs, direct operational costs, indirect operational costs/overhead, external contracts, and stewardship costs (Table 1).

Table 1 Accounting category definitions

\begin{tabular}{ll}
\hline Accounting category & \multicolumn{1}{c}{ Definition } \\
\hline Operational staff costs & $\begin{array}{l}\text { Salary and fringe benefits of all staff involved directly in generating } \\
\text { the results and the outcome - i.e. the PI, research associates, and } \\
\text { technicians } \\
\text { Direct operational costs }\end{array}$ \\
$\begin{array}{l}\text { Travel and supplies (reagents, kits, fertilisers, pesticides, } \\
\text { transportation of materials), laboratory bench costs (except for CIP) }\end{array}$ \\
Indirect operational & $\begin{array}{l}\text { Laboratory bench costs (except for MSU charging 50\% of staff } \\
\text { costs), greenhouse costs, IT services, and institutional overhead } \\
(24 \% \text { of staff, bench fee, and IT costs }+5 \% \text { of external contract } \\
\text { costs), including capital depreciation }\end{array}$ \\
External contract costs & $\begin{array}{l}\text { Costs of outsourcing work to subcontractors (confined field trials, } \\
R \text { protein production, oral gavage, etc.) }\end{array}$ \\
Stewardship costs & $\begin{array}{l}\text { Costs of strictly necessary public advocacy, lobbying, responding to } \\
\text { NCA requests }\end{array}$ \\
\hline
\end{tabular}

These processes are briefly summarised below, as well as in Figure 1 flowchart. A more detailed description, including detailed descriptions of the sub-processes and their respective outcomes, can be found in the supplementary document 'Guidelines and definitions for the processes to be cost assessed by the participating institutions', available as supplementary materials.

Accounting categories are summarised in Table 1. Although the participating institutions have different accounting practices, care was taken not to double count costs. For example, MSU calculates indirect costs as $50 \%$ of the staff costs, and laboratory bench fees constitute the direct cost. In CIP's case, lab bench fees are part of indirect costs, along with IT services and overhead, where overhead is calculated as $24 \%$ of the staff, bench fee, and IT services costs, plus $5 \%$ of any external contract costs. We assume no capital purchase, i.e. the participating institutions have the facilities and the equipment necessary to develop the product. 
Figure 1 Flowchart of the four processes involved in the development and release of LBr potato in one developing country (see online version for colours)

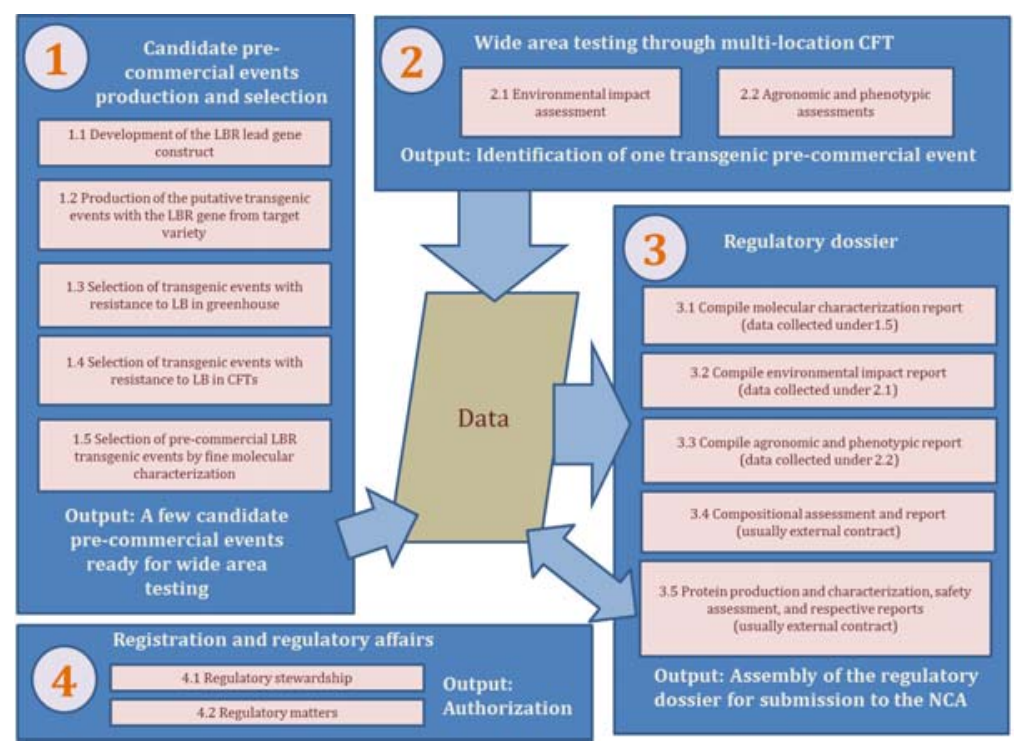

\subsubsection{Process 1: candidate pre-commercial events production and selection}

In this process, the technology used in the proof-of-concept is applied to the target variety in order to obtain a reduced number of candidate pre-commercial transgenic events. Once the lead gene construct has been developed, a relatively large number of explants is screened by successive procedures in order to

1 identify transgenic events from among the explants

2 remove the transgenic events with backbone vector sequences

3 select the transgenic events exhibiting high resistance to LB in confined field trials (CFT)

4 select the transgenic events with the minimum copy number of $R$ genes.

The output of this process is a small number of candidate pre-commercial transgenic events selected for wide area testing, as well as molecular characterisation data to be used in the compilation of the regulatory dossier later on.

\subsubsection{Process 2: wide area testing through multi-location trials}

In this process, the candidate pre-commercial transgenic events are evaluated under normal and/or managed field conditions for resistance to LB. Depending on the diversity of the environment where the potato variety is grown in the target country, CFTs are conducted in multiple locations to assess any environmental effect on the trait performance. At the same time, the agronomic performance of the candidate pre-commercial transgenic events are assessed and compared to the non-transformed counterpart. This may include testing the number and kinds of fungicide spray needed to 
prevent productivity losses under exceptionally heavy disease pressure. These field trials also test for any negative impact of the trait on key performance attributes, yield or tuber quality, or potential negative environmental interactions. At the end of this process, one pre-commercial transgenic event is identified. In this study, the participating institutions exclude any costs incurred in demonstration trials conducted for the purpose of stimulating stakeholder's interests.

\subsubsection{Process 3: regulatory dossier}

In this process, the best pre-commercial transgenic event (selected under Process 2) is examined to ensure compliance with all regulatory requirements established by the National Competent Authority (NCA), and the corresponding regulatory dossier is compiled for submission to the NCA. Much of the data required for this examination have already been generated and collected under previous sub-processes: molecular characterisation data are generated under sub-process 1.5; while the environmental impact and phenotypic/agronomic data are generated under sub-processes 2.1 and 2.2. Therefore the respective costs assessed under Process 3 are only those incurred in the processing, filing, and redaction of the results of the laboratory and the field observations for the regulatory dossier. Only the compositional assessment data and the safety assessment data (protein production and characterisation data for allergenicity and toxicity assessments) are generated and collected under Process 3. At the end of this process, a regulatory dossier is ready for submission to the NCA.

\subsubsection{Process 4: registration and regulatory affairs}

Once the regulatory dossier has been submitted it must be defended, amended, and completed before the NCA authorises commercial production. This process may involve a variety of activities, including public advocacy, lobbying, and submission of additional information not included in the original dossier. In this study, it is assumed that any requests made by the NCA will concern existing information and data that were not included in the regulatory dossier, or data included in the regulatory dossier but not analysed using the methodology favoured by the examiners, or not discussed at the level of details desired by the examiners. Hence, participating institutions assessed the cost and duration of this process assuming that the NCA makes its requests and decisions solely on scientific bases directly related to the regulatory dossier, and that it does not request further regulatory trials. The end product of this process is the authorisation of commercial production of one transgenic $\mathrm{LBr}$ potato variety in one of the target countries.

\subsection{Taking account technical parameters}

The participating institutions completed their cost assessments in such a way as to explicitly account for the influence of four technical parameters having a significant impact on total cost. These are the selection efficiency parameters determining the number of events handled during each sub-process of pre-commercial candidate event selection (Process 1). Specifically, they are: 
1 transformation efficiency of the target variety $\left(E_{1}\right)$ : the ease of genetic transformation differs substantially between varieties, gene constructs, delivery method, and laboratory competencies

2 selection efficiency for removal of events without backbone vector sequences $\left(E_{2}\right)$ : transfer of the genes into the recipient variety can sometimes include other DNA from the vector which is undesirable

3 highly resistant event selection efficiency $\left(E_{3}\right)$ : the desirable level of resistance depends on the environmental conditions and best guess of the PI as to what level is needed

4 southern blot efficiency $\left(E_{4}\right)$ : depending on experimental conditions, the genes may be inserted as multiple copies into the plant genome, of which the PI will select a single copy insertion for practical reasons.

A fifth, non-technical, parameter - the number of desired pre-commercial events the institution aims to have at the end of screening - also influences Process 1 costs, and is taken into consideration:

5 desired number of pre-commercial events $(n)$ : different PIs have different ideas as to how many pre-commercial events are needed for wide area testing.

Assuming that the institutions are cost minimisers, and that prices and other direct costs per event do not change with changes in the quantity of explants or events handled in Process 1, then the envelope theorem tells us that each institution's cost function will move along a fixed technical envelope, as illustrated in Figure 2. Since costs decrease with increased screening efficiency, all of the institutions' technical envelopes will exhibit the same monotonically decreasing convex shape, although the slope of the envelope may vary from one institution to another in accordance with variations in local prices and direct costs per event. It will be seen below that Process 1 costs can be quite sensitive to small movements along these technical envelopes.

Figure 2 Illustration of the technical envelope along which the institutions' cost functions move for a given screening efficiency parameter (see online version for colours)

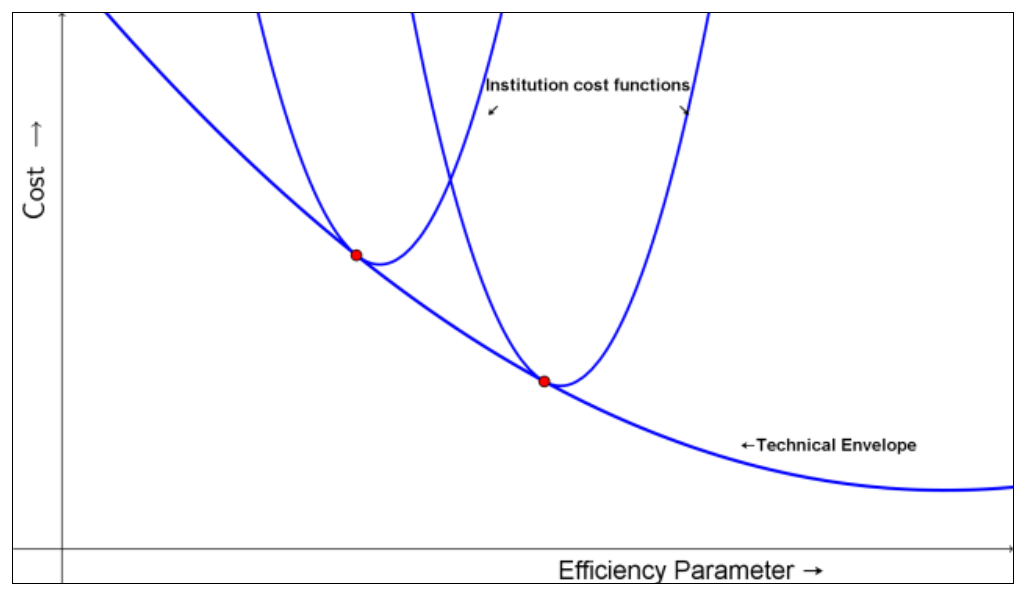

Note: A given institution's cost function is shown at two different efficiency values. 
The total number of explants $N_{1}$ needed at the start of Process 1 to reach a desired number $n$ of pre-commercial candidate events is, then:

$$
N_{1}=\frac{n}{E_{1} E_{2} E_{3} E_{4}}
$$

and the number handled at any particular stage $k$ of screening is:

$$
N_{k}=n \prod_{i=k}^{4} \frac{1}{E_{1}} ; \quad i, k=1,2,3,4
$$

Process 1 direct cost is then calculated as:

$$
D C=\sum_{i=1}^{4} P_{i} N_{i}=P_{1} N_{1}+P_{2} N_{2}+P_{3} N_{3}+P_{4} N_{4}
$$

where $P_{i}$ is the marginal direct cost per event in the $i^{\text {th }}$ stage of screening. The $P_{i}$ are calculated simply by dividing the direct cost which the institution reports for each sub-process by the number of events or explants the institution handles under that sub-process. Of course, if a single stage of screening involves different activities and different direct costs, $P_{i}$ must be disaggregated accordingly. For example, in CIP's case, screening for high resistance to late blight occurs partly in the greenhouse, and partly in confined field trials. Each of these components incurs a different set of direct costs, and so each of these sets of direct costs must be individually divided by the number of events handled, meaning that $P_{3}$ must be calculated as the sum of two independent components $\left(P_{3}=P_{3 a}+P_{3 b}\right)$.

The time duration of Process 1 is also sensitive to the efficiency parameters and thus any time-dependent costs as well. The Process 1 staff operating costs are calculated as:

$$
S C=w_{1} T_{1} N_{1}+w_{2} T_{2} N_{2}+w_{3} T_{3} N_{3}+w_{4} T_{4} N_{4}
$$

where the $T_{i}$ are the respective time durations per event for each of the stages, calculated in a way analogous to how the $P_{i}$ are calculated. The $w_{i}$ are the staff costs per unit time, a straightforward calculation of the number of each type of staff involved in the $i^{\text {th }}$ screening stage (lab technician, research associate, principal investigator, etc.) times the respective annual salary, times the percentage time commitment. In the CIP cost assessment, accounting practices are such that fees can also be calculated in this way.

\subsection{Taking account of exogenous disturbances}

Finally, in this study care is taken to control for exogenous disturbances. The participating institutions were asked to assess their costs under the assumption that activities are completed without any unexpected delays or expenditures of resources (resulting, for example, from equipment failure, funding discontinuity, maternity leaves, unpredictable administrative obstacles, etc.). If the institution believed a disturbance was likely to occur during some sub-process, it was instructed to indicate this in a separate column, with some indication as to how probable the disturbance was and how much it might inflate the cost and timeline. 


\section{Results}

\subsection{Overall cost assessment}

After sharing, in summer 2013, the guidelines and cost template files with the participating institutions and their respective partners, the data provided back in fall 2013 were verified to avoid double counting of costs. The gross cost assessments are tabulated by process in Table $2 .^{1}$ These costs are examined in more detail for each process below.

Table 2 The cost assessments

\begin{tabular}{|c|c|c|c|c|c|}
\hline \multirow[b]{2}{*}{ Process 1 subtotal } & \multirow{2}{*}{$\begin{array}{l}\text { Summary } \\
\text { Candidate pre-commercial } \\
\text { event production and selection }\end{array}$} & \multicolumn{2}{|c|}{$C I P$} & \multicolumn{2}{|l|}{$C U$} \\
\hline & & $\$ 929,028$ & $58 \%$ & $\$ 530,250$ & $39 \%$ \\
\hline Process 2 subtotal & $\begin{array}{l}\text { Wide area testing through } \\
\text { multi-location CFTs }\end{array}$ & $\$ 396,412$ & $25 \%$ & $\$ 335,530$ & $25 \%$ \\
\hline Process 3 subtotal & Regulatory dossier & $\$ 212,750$ & $13 \%$ & $\$ 311,974$ & $23 \%$ \\
\hline Process 4 subtotal & $\begin{array}{l}\text { Authorisation of commercial } \\
\text { production of one transgenic } \\
\text { LBr potato variety in one } \\
\text { of the target countries }\end{array}$ & $\$ 52,300$ & $3 \%$ & $\$ 180,541$ & $13 \%$ \\
\hline Total & & $\$ 1,590,490$ & $100 \%$ & $\$ 1,358,295$ & $100 \%$ \\
\hline
\end{tabular}

Note: Values in USD

\subsubsection{Cost assessment of process 1 (candidate pre-commercial transgenic event production and selection)}

The Process 1 gross costs to the participating institutions diverge significantly. One might speculate that the divergence is rooted in local differences in the cost of obtaining supplies. Certainly, this is true to some extent. CIP developed its candidate pre-commercial events at its headquarters in Lima, Peru, where many lab supplies must be imported at a relatively high price. MSU, on the other hand, developed its candidate pre-commercial events in the USA, where most of the required lab supplies are manufactured and can thus be acquired at a relatively low price in a timely manner. However, when direct costs are broken down per event (Table 3), it becomes clear that differing supply prices can explain only a small part of the divergence.

In sub-processes 1.2 and 1.4, the institutions' direct costs per event converge. They only differ significantly in Sub-processes 1.3 and 1.5, but this is not due to supply prices, but rather to a comparative advantage in personnel, lab facilities, and field trial access at MSU which permit it to skip greenhouse screening altogether, and to complete fine molecular characterisation using its own resources, without the need for an external contract. The extra direct cost incurred by CIP as a result of its comparative disadvantage can be worked out from Table 3 and is not much $-\$ 73,000$. However, when the staff costs, indirect costs, and external contracts incurred by CIP during these two sub-processes are added in, the total extra cost reaches $\$ 304,172$, a figure large enough to explain most of the divergence between the two institutions in the Process 1 gross cost. 
Table 3 Process 1 direct costs per event $\left(P_{i}\right)$, and number of explants/events handled in each sub-process

\begin{tabular}{|c|c|c|c|c|c|}
\hline \multirow[b]{2}{*}{ Sub-process } & \multirow{2}{*}{$\begin{array}{c}\text { Screening status of } \\
\text { events being handled in } \\
\text { sub-process }\end{array}$} & \multicolumn{2}{|l|}{$C I P$} & \multicolumn{2}{|c|}{$M S U / C U$} \\
\hline & & $\begin{array}{c}\text { Number of } \\
\text { explants/events } \\
\text { handled }\end{array}$ & $\begin{array}{c}\text { Direct } \\
\text { cost per } \\
\text { event }\end{array}$ & $\begin{array}{c}\text { Number of } \\
\text { explants/events } \\
\text { handled }\end{array}$ & $\begin{array}{l}\text { Direct } \\
\text { cost per } \\
\text { event }\end{array}$ \\
\hline \multirow[t]{2}{*}{1.2} & Starting explants & 5,625 & $\$ 12$ & 2,000 & $\$ 12$ \\
\hline & Transgenic events & 225 & $\$ 59$ & 100 & $\$ 47$ \\
\hline 1.3 & $\begin{array}{l}\text { Events with backbone } \\
\text { vector sequences removed } \\
\text { and tested in greenhouse }\end{array}$ & 150 & $\$ 233$ & $0^{*}$ & $0^{*}$ \\
\hline 1.4 & $\begin{array}{l}\text { Events tested in } \\
\text { confined field trials }\end{array}$ & 150 & $\$ 100$ & 67 & $\$ 150$ \\
\hline 1.5 & $\begin{array}{l}\text { Events with high } \\
\text { resistance to } \mathrm{LBr}\end{array}$ & 15 & $\$ 2,667$ & $0 * *$ & $0 * *$ \\
\hline
\end{tabular}

Notes: *MSU had easy access to confined field trials, and so could skip the greenhouse (sub-process 1.3).

**MSU could ensure high enough quality molecular characterisation that, unlike CIP, it did not have to repeat or 'polish' fine molecular characterisation of the pre-commercial events (sub-process 1.5).

The screening efficiency parameters reported by the participating institutions are presented in Table 4 and are quite similar, if not exactly the same.

Table 4 Event screening efficiency parameters

\begin{tabular}{lcc}
\hline & $C I P$ & $M S U / C U$ \\
\hline Transformation efficiency of target variety $\left(E_{1}\right)$ & $4 \%$ & $5 \%$ \\
Selection of events without backbone vector sequences $\left(E_{2}\right)$ & $67 \%$ & $67 \%$ \\
Highly resistant event selection efficiency $\left(E_{3}\right)$ & $10 \%$ & $14 \%$ \\
Southern blot efficiency $\left(E_{4}\right)$ & $33 \%$ & $33 \%$ \\
Desired number of pre-commercial events $(n)$ & 5 & 3 \\
\hline
\end{tabular}

However, it is interesting to note that even the slight differences present in Table 4 can make a big difference in cost. In a ceteris paribus analysis where CIP's screening parameters are adjusted to match those of MSU, the resulting shift in CIP's cost function along the technical envelope is enough to lower its Process 1 cost to MSU's level (Table 5). (Conversely, MSU's Process 1 cost can be inflated to CIP's level if its parameter values are adjusted to match those of CIP.) In theory, then, CIP could make up for its comparative disadvantage in sub-processes 1.3 and 1.5 by very small increases in its screening efficiency parameters. Process 1 cost sensitivity to changes in the screening parameters is examined more closely in the sensitivity analysis section.

Table 5 Ceteris paribus comparison of Process 1 costs

\begin{tabular}{lccc}
\hline Institution & Gross & Ceteris paribus & Change \\
\hline CIP & $\$ 929,028$ & $\$ 566,715$ & $-39 \%$ \\
MSU/CU & $\$ 530,250$ & $\$ 1,251,656$ & $+136 \%$ \\
\hline
\end{tabular}




\subsubsection{Cost assessment of process 2 (wide area testing through multi-location CFTS)}

The participating institutions reported the costs of conducting wide area testing in three locations over three years, as required by their respective NCAs. These were of $\$ 396,412$ and $\$ 335,530$ for CIP and CU respectively (Table 2). This included the costs of non-target organism studies and other environmental studies anticipated to be required, as well as greenhouse studies and planting material multiplication. The cost assessments for this process agreed closely.

\subsubsection{Cost assessment of process 3 (regulatory dossier preparation)}

The cost assessments submitted by the participating institutions begin to diverge in Process 3 with $\$ 212,750$ and $\$ 311,974$ for CIP and CU respectively. This is to be expected in some extent, as the costs incurred in this process depend significantly upon differences in the expected regulatory requirements of the respective NCAs. Indeed, regulatory agencies in Uganda, India and Indonesia have not defined exactly which requirements must be met with new experimental data and which may be validated by already existing published studies. Some of the divergence can also be attributed to the different ways in which the participating institutions implement this process. CIP reported that it hires outside expertise to compile most of the regulatory dossier. CU, on the other hand, reported that it relies upon its own scientists and PIs to do this, and hires a consultant only at the end of the process in order to conduct a final review of the dossier.

\subsubsection{Cost assessment of process 4 (regulation and regulatory affairs)}

The cost assessments also diverged in Process 4 with $\$ 52,300$ and $\$ 180,541$ for CIP and CU respectively. Again, this is to be expected, as costs depend significantly upon local differences in the way that the NCA conducts the regulatory approval process. In this process, as in Process 3, CIP's assessment was again based on an external contract with a regulatory compliance expert, while $\mathrm{CU}$ relies upon its own human resources.

\subsection{Timelines}

In addition to the cost assessment, the participating institutions and their partners completed the timelines in Figure 3. At the time of this study, both institutions were somewhere between Process 2 and 4 . The durations of processes not yet completed are therefore estimates.

The timelines are broadly similar, but reflect key differences in the expectations and circumstances faced by each institution. CIP spends one and a half years longer in the laboratory than the MSU/CU program because the latter can omit the greenhouse screening of high level of resistance to LB. Conversely, CIP expects to complete regulatory approval in just one year as opposed to CU's three years because it will hire an outside biosafety expert with large experience in dossier development and submission. The estimated duration of the regulatory approval process is something of an optimistic guess made by the project scientists based upon knowledge of the scientific activities involved in the process, and upon a rational expectation of how long it should take to complete such activities from a purely technical point of view. In the specific case of $\mathrm{LBr}$ 
potato, moreover, there is good reason to expect that the GM technology will provoke relatively little political opposition because the transferred genes are already present in currently consumed potato varieties. This is thus an estimate which does not necessarily reflect the often formidable non-technical - in particular, the political, legal, and bureaucratic - hurdles involved in the approval process; and is thus not necessarily representative of the average historical experience of other research organisations pursuing release of other GM products in other developing countries. For example, MON15985 was approved in 2002 in the USA, but took another four and six years to de approved in India and Burkina Faso respectively.

Figure 3 Timelines for product development until regulatory dossier is submitted and received as complete (see online version for colours)

\begin{tabular}{|c|c|c|c|c|c|c|c|c|c|c|c|}
\hline \multicolumn{12}{|c|}{ CIP Timeline } \\
\hline Process & Process Summary & Duration & Year & Year 2 & Year 3 & Year 4 & Year 5 & Year 6 & Year 7 & Year 8 & Year \\
\hline & & (Years) & $2]^{3}$ & & \begin{tabular}{ll|l|l|l|}
1 & 2 & 3 \\
\end{tabular} & $\begin{array}{l}1 \mid 2[3 \\
\end{array}$ & $1] 2[3$ & \begin{tabular}{|l|l|l|l|}
4 & 1 & 2 & 3 \\
\end{tabular} & $4[1$ & 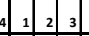 & \begin{tabular}{|l|l|l|l|} 
& 3 & 4 & 4 \\
\end{tabular} \\
\hline 1 & $\begin{array}{l}\text { Candidate pre-commercial event } \\
\text { production and selection }\end{array}$ & 4.75 & & & & & & & & & \\
\hline 2 & Wide area testing & 2 & & & & & & & & & \\
\hline 3 & Regulatory dossier & 0.5 & & & & & & & & & \\
\hline 4 & Registration and regul atory affairs & 1 & & & & & & & & & \\
\hline \multicolumn{12}{|c|}{ MsU/CU Timeline } \\
\hline Process & Process Summary & Duration & Year 1 & Year 2 & Year 3 & Year 4 & Year 5 & Year 6 & Year 7 & Year 8 & Year 9 \\
\hline & 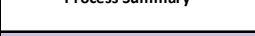 & (Years) & 4 & & 1]2] & & 2 & & & & \\
\hline 1 & $\begin{array}{l}\text { Candidate pre-commercial event } \\
\text { production and selection }\end{array}$ & 3.42 & & & & & & & & & \\
\hline 2 & Wide area testing & 1.67 & & & & & & & & & \\
\hline 3 & Regulatory dossier & 0.83 & & & & & & & & & \\
\hline 4 & Registration and regul atory affairs & 3.00 & & & & & & & & & \\
\hline
\end{tabular}

\subsection{Exogenous disturbances}

The participating institutions indicated that if exogenous disturbances were to happen, these would most likely to occur during wide area testing in Process 2, or during regulatory approval in Process 4. In both cases, the likely source of these disturbances was characterised as a strong international anti-GMO lobby stirring up opposition among local farmers and communities.

In Process 2, these local opponents might demand that the NCA call for deeper scrutiny of field trials conducted by the institution, potentially resulting in the delay or loss of cropping seasons. Such delays would mean an increase in staff and stewardship costs on the order of several tens of thousands of dollars.

In Process 4, the anti-GMO lobby could delay or block approval by filing additional requests or litigation before the NCA. In recent years, this has actually happened in India and China. Such delays would mean an increase in stewardship costs also on the order of several tens of thousands of dollars.

Note that it is not unheard of that such disturbances could also occur during confined field trials in Process 1. In 2011, for example, field trials of $\mathrm{LBr}$ potato conducted by Ghent University in Belgium were damaged by anti-GMO activists. However, the 
institutions participating in the present study indicated that the likelihood of disturbances in Process 1 was low.

\subsection{Sensitivity analysis}

Sensitivity analysis was performed on salaries, fees, and the screening efficiency parameters. A simultaneous $10 \%$ increase in all staff salary and lab fee parameters resulted in negligible increases in total cost (about 2\%). Perturbations in the screening efficiency parameters resulted in a more appreciable impact on total cost, and are thus worthy of closer inspection.

Each institution's cost sensitivity to changes in transformation efficiency and highly resistant event screening efficiency is examined in Figure 4. Here it is evident that small decreases in efficiency result in marginally steep increases in cost, while increases result in marginally shallow cost reductions. This pattern is repeated for the two efficiency parameters not included in this figure. Cost sensitivity to changes in the parameter will necessarily be higher the later the screening procedure occurs in Process 1 [a mathematical consequence of equations (1)-(3)], but does not surpass a $60 \%$ increase.

Figure 4 Sensitivity analysis of two parameters affecting process 1 costs (see online version for colours)
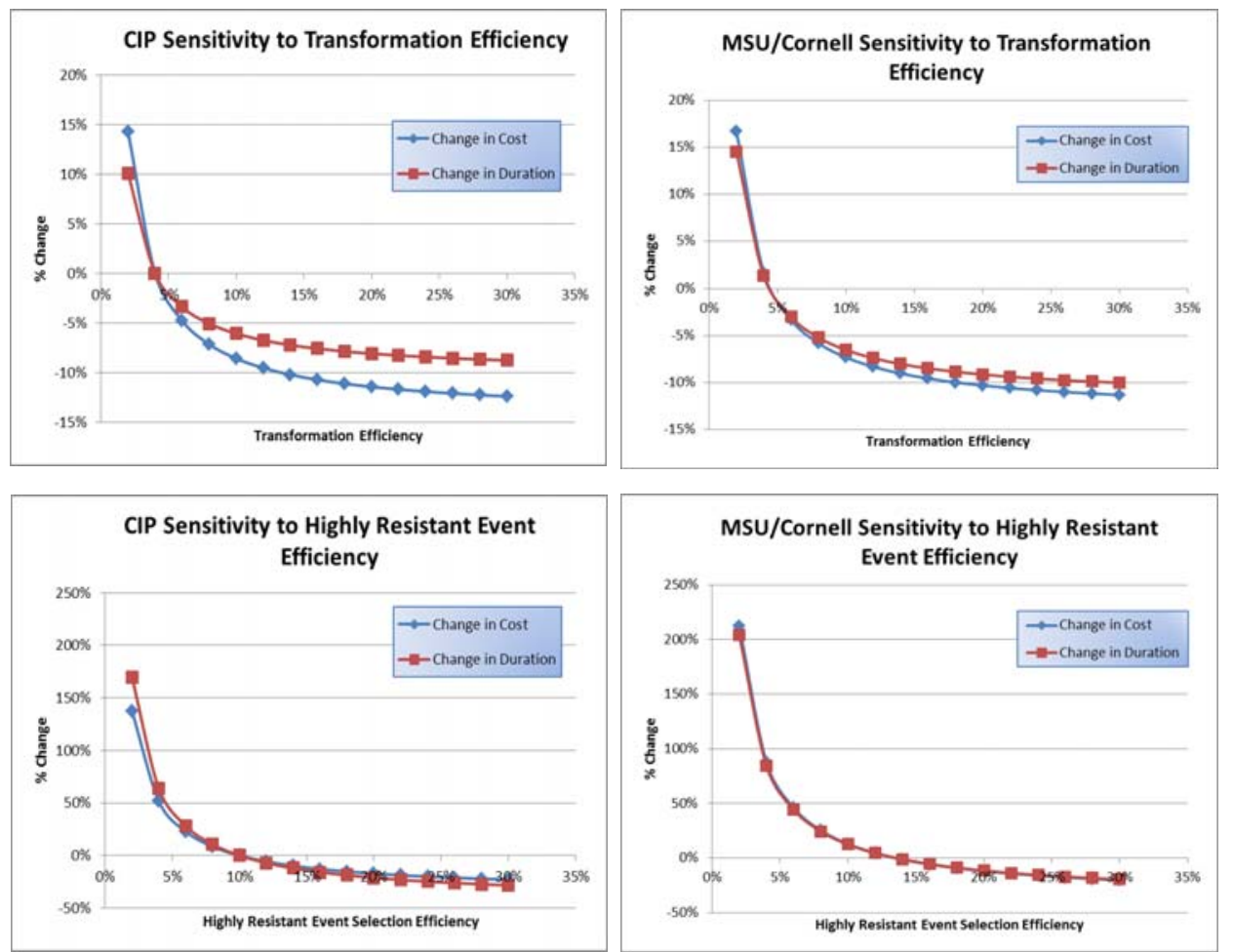

Notes: In each of these graphs, the institution's baseline parameter value is indicated where the curve crosses the $\mathrm{x}$-axis. The institution's cost sensitivity to changes in the parameter can be read off the $y$-axis. 


\section{Discussion}

The two not-for-profit institutions' cost assessments agree closely in their bottom line: For \$1.3-1.5 million, over eight to nine years, one $\mathrm{LBr}$ variety can be made available to resource-poor farmers in a developing country. A significant difference in the institutions' Process 1 cost assessments is explained by comparative advantages which allow MSU to skip sub-processes 1.3 and 1.5. Remarkably, this divergence would largely vanish given very small adjustments to the institutions' screening efficiency parameters and to the number of desired pre-commercial events.

A smaller divergence in the Process 1 and 2 cost assessments reflects each institution's perceived level of regulatory dossier requirements, revisions, stewardship, and engagement with the regulatory authorities in their respective target country.

In any case, both the variance and the magnitude of the cost assessments completed by the participating institutions are much lower than that of the private sector assessments conducted by Kalaitzandonakes et al. (2006) and by McDougall (2011).

The institutions participating in this study acknowledge that costs could be inflated by exogenous disturbances. Such disturbances, however, would inflate the bottom line by a relatively insignificant amount (on the order of several tens of thousands of US dollars). The primary impact is more on postponing trials and/or deregulation than increasing costs. The results of sensitivity analysis suggest, moreover, that total cost is insensitive to changes in salary and lab fee parameters. Changes in the Process 1 screening efficiency parameters do result in appreciable changes in total cost (in the range of $10 \%-60 \%$ ). However, even a $60 \%$ increase in total cost would not bring the bottom line of the notfor-profit institutions anywhere near the private sector cost estimates.

It should be kept in mind, moreover, that changes in the Process 1 parameters can lower costs as well as raise them - and in some cases a cost reduction is more probable than an increase. For example, the participating institutions chose to transform target varieties with transformation efficiencies of $4 \%$ and $5 \%$. It is unlikely that an institution would attempt to develop a transgenic variety with transformation efficiency much lower than $4 \%$, but quite possible that it would choose target varieties with higher transformation efficiencies. The corresponding reduction in cost can be worked out from Figure 3.

From a purely scientific perspective, moreover, it can be argued that Process 2 and 3 costs should be much lower. For example, the environmental impact assessment in Process 2 might not be scientifically justified since the same $R$ genes are already present in conventional potato varieties which are currently cultivated and consumed. For the same reason, glycoalkaloid analysis in Process 3 is certainly justified, but any compositional assessment beyond that may not be needed. According to a recent paper, "after two decades of compositional equivalence studies... there appears to be overwhelming evidence that transgenesis is less disruptive of crop composition compared with traditional breeding, which itself has a tremendous history of safety" (Herman and Price, 2013). How much would the total cost be without these expenditures? CIP made the calculation and found that its wide area testing (Process 2) costs would be reduced by $50 \%$ and its regulatory dossier (Process 3 ) costs would be reduced by $52 \%$, resulting in an overall cost reduction of $20 \%$. 
Why is the cost of pursuing a GM program so much lower for not-for-profit programs? First of all, there are some fairly obvious reasons. Private sector corporations have much larger budgets than not-for-profit enterprises, and pursue grand strategies commensurate with those budgets. Their interests might span a number of different industries; involve several projects in tandem, several end-uses, and several markets. In pursuit of the development of products with billion dollar market potential, they do not hesitate to pay top dollar for personnel and state-of-the-art technology. Not-for-profit institutions, by contrast, are more surgical in their approach. They pursue highly specific goals for specific populations in specific countries. They do not attempt to sustain the massive in-house capacity of their private sector counterparts, but rather modify their capacity as they go, and as necessary to fulfil the objectives of the specific project at hand.

And then there are some less obvious, more speculative reasons. It may be that the private corporations do much more testing than is strictly necessary for the regulatory dossier in order to increase public confidence in their competence. Finally, one might speculate that the corporations participating in the Kalaitzandonakes et al. (2006) and McDougall (2011) studies deliberately exaggerated their costs out of a competitive self-interest. Venture capitalists would feel uncomfortable starting up in an industry with perceived high risks if not associated with high costs for safety assessment of the product.

\section{Conclusions}

The cost to not-for-profit institutions of developing a transgenic potato variety with late blight resistance for release in one developing country is well under \$2 million USD over eight to nine years. This cost figure is less than the private sector costs by two orders of magnitude.

Evidently, costs might vary from one not-for-profit institution to another based on each institution's screening efficiency parameters and on the country in which the institution is seeking regulatory approval, but the variation is not great and could reduce costs as well as raise them. Exogenous disturbances might cause a loss of cropping season(s) or a delay of several years due to moratorium - and hence a great deal of frustration for the implementing institution - but the resulting increase in cost will not be proportional to the frustration. Based on purely scientific considerations, moreover, some of the costs incurred during wide area testing and the building of the regulatory dossier might not be justified for this particular trait, and their exclusion would reduce costs even further. All in all, these findings suggest that the cost of developing and bringing to market one transgenic staple crop variety in one developing country is affordable by current not-for-profit institutions engaged in genetic engineering for crop improvement. 


\section{References}

Adiyoga, W. (2009) 'Costs and benefits of transgenic late blight resistant potatoes in Indonesia', in Norton, G.W. and Hautea, D.M. (Eds.): Projected Impacts of Agricultural Biotechnologies for Fruits and Vegetables in the Philippines and Indonesia, pp.86-104, International Service for the Acquisition of Agri-biotech Applications and the SEAMEO Southeast Asian Regional Center for Graduate Study and Research in Agriculture, Los Baños, Laguna 4030, Philippines.

Ambarwati, A.D., Herman, M., Purwito, A., Sumaraw, S.M. and Aswidinnoor, H. (2013) 'Resistance evaluation on populations of crosses between transgenic potato Kathadin $R B$ and non-transgenic Atlantic and Granola to late blight (phytophthora infestans) in confined field trial', Indonesian Journal of Agricultural Science, Vol. 12, No. 1, pp.33-39.

Bernauer, T., Tribaldos, T., Luginbühl, C. and Winzeler, M. (2011) 'Government regulation and public opposition create high additional costs for field trials with GM crops in Switzerland', Transgenic Research, Vol. 20, No. 6, pp.1227-1234.

Brookes, G. and Barfoot, P. (2012) GM Crops: Global Socio-Economic and Environmental Impacts 1996-2010, PG Economics Ltd. [online] http://www.pgeconomics.co.uk/page/ 33/global-impact-2012 (accessed 31 January 2013).

Falck-Zepeda, J., Yorobe Jr., J., Husin, B.A., Manalo, A., Lokollo, E., Ramon, G. and Zambrano, P. (2012) 'Estimates and implications of the costs of compliance with biosafety regulations in developing countries', GM Crops and Food, Vol. 3, No. 1, pp.52-59.

Fry, W. (2008) 'Phytophthora infestans: the plant (and $R$ gene) destroyer', Molecular Plant Pathology, Vol. 9, No. 3, pp.385-402.

Halterman, D.A., Kramer, L.C., Wielgus, S. and Jiang, J. (2008) 'Performance of transgenic potato containing the late blight resistance gene RB', Plant Disease, Vol. 92, No. 3, pp.339-343.

Haverkort, A.J., Boonekamp, P.M., Hutten, R., Jacobsen, E., Lotz, L.A.P., Kessel, G.J.T. and Van der Vossen, E.A.G. (2008) 'Societal costs of late blight in potato and prospects of durable resistance through cisgenic modification', Potato Research, Vol. 51, No. 1, pp.47-57.

Haverkort, A.J., Struik, P.C., Visser, R.G.F. and Jacobsen, E. (2009) 'Applied biotechnology to combat late blight in potato caused by phytophthora infestans', Potato Research, Vol. 52, No. 3, pp.249-264.

Herman, R.A. and Price, W.D. (2013) 'Unintended compositional changes in genetically modified (GM) crops: 20 years of research', Journal of Agricultural and Food Chemistry, Vol. 61, No. 48, pp.11695-11701.

Islam, S.F. and Norton, G.W. (2007) 'Late blight resistant potato in Bangladesh', in Selvaraj, K.N., Ramasamy, C. and Norton, G.W. (Eds.): Economic and Environmental Benefits and Costs of Transgenic Crops: Ex-Ante Assessment, pp.107-119, Tamil Nadu Agricultural University, Coimbatore, India.

Jo, K.R., Kim, C.J., Kim, S.J., Kim, T.Y., Bergervoet, M., Jongsma, M.A. and Vossen, J.H. (2014) 'Development of late blight resistant potatoes by cisgene stacking', BMC Biotechnology, Vol. 14, No. 1, p.50.

JRC (2015) Deliberate Release and Placing on the EU Market of GMOs - GMO Register [online] http://gmoinfo.jrc.ec.europa.eu/gmp_browse.aspx (accessed 5 March 2015).

Kalaitzandonakes, N., Alston, J.M. and Bradford, K.J. (2006) 'Compliance costs for regulatory approval of new biotech crops', Regulating Agricultural Biotechnology: Economics and Policy, Natural Resource Management and Policy, Vol. 30, pp.37-57, Springer, USA.

Klumper, W. and Qaim, M. (2014) 'A meta-analysis of the impacts of genetically modified crops', PLoS ONE, Vol. 9, No. 11, p.e111629, doi:10.1371/journal.pone.0111629.

Kuhl, J.C., Zarka, K., Coombs, J., Kirk, W.W. and Douches, D.S. (2007) 'Late blight resistance of $R B$ transgenic potato lines', Journal of the American Society for Horticultural Science, Vol. 132, No. 6, pp.783-789.

Manalo, A.J. and Ramon, G.P. (2007) 'The cost of product development of Bt corn event MON810 in the Philippines', AgBioForum, Vol. 10, No. 1, pp.19-32. 
McDougall, P. (2011) The Cost and Time Involved in the Discovery, Development, and Authorization of a New Plant Biotechnology Derived Trait, A Consultancy study for Crop Life International, Midlothian, UK [online] http://www.croplife.org/PhillipsMcDougallStudy (accessed 15 September 2013).

Selvaraj, K.N. (2007) 'Late blight resistant potato in India', in Selvaraj, K.N., Ramasamy, C. and Norton, G.W. (Eds.): Economic and Environmental Benefits and Costs of Transgenic Crops: Ex-Ante Assessment, pp.47-56, Tamil Nadu Agricultural University, Coimbatore, India.

Song, J., Bradeen, J.M., Naess, S.K., Raasch, J.A., Wielgus, S.M., Haberlach, G.T. and Jiang, J. (2003) 'Gene $R B$ cloned from solanum bulbocastanum confers broad spectrum resistance to potato late blight', Proceedings of the National Academy of Sciences USA, Vol. 100, No. 16, pp.9128-9133.

Zhu, S., Li, Y., Vossen, J.H., Visser, R.G. and Jacobsen, E. (2012) 'Functional stacking of three resistance genes against phytophthora infestans in potato', Transgenic Research, Vol. 21, No. 1, pp.89-99.

\section{Notes}

1 A more detailed table reporting the costs and durations of each sub-process is available as supplementary materials. 